ORIGINAL ARTICLE

\title{
Profile Of new Patients attending Psychiatry Out-patient Department at Lumbini Medical College-Teaching Hospital, Palpa
}

\author{
Sharma B' ${ }^{1}$ Devkota $A^{1}$, Pant SC ${ }^{3}$
}

\begin{abstract}
1. Lecturer, Department of Psychiatry, LMC-TH, Palpa, Nepal 2. Associate Professor, Department of Psychiatry, LMC-TH, Palpa, Nepal
\end{abstract}

E-mail *Corresponding author: vasker63@yahoo.com

\begin{abstract}
Introduction: Study on prevalence of psychiatric disorders in Palpa and nearby districts which lie in western Nepal, is not much studied till date. We therefore conducted this study aiming to see the pattern of psychiatric illness in an Outpatient Department of Lumbini Medical College which is a tertiary care centre located in Palpa district.
\end{abstract}

Material And Method: : This is a retrospective study where outpatient record of all new cases attending the Psychiatry OPD from 29th Oct 2014 to 29th Dec 2014 were studied and statistical analysis were done. The number of new patients were 107.

Results: Out of 107 patients, $60.74 \%$ (65)) were females and $39.26 \%$ (42) were males. Patients of age group 3140yrs showed the largest proportion (27.49\%) followed by age group 41-50yrs (24.29\%).

Majority cases were illiterate $(69.15 \%)$ followed by primary level of education (14.95\%). The occupation of most of the cases were household work (35.51\%) followed by farming (31.77\%). Anxiety disorder (27.10\%) was the most frequent diagnosis ahead of "Others" (18.69\%) followed by depressive disorder (15.88\%).

Conclusion: Most of the new patients attending the psychiatry OPD of Lumbini Medical College were females, of 31-40 age group and most of the patients suffered from anxiety disorders.

\section{Keywords: Psychiatric Illness, LMC, Mental Illness}

\section{INTRODUCTION}

Study on prevalence of psychiatry disorders in Palpa and nearby districts which lies in western Nepal is not much studied till date. We therefore conducted this study aiming to see the pattern of psychiatric illness in an Out Patient department of Lumbini Medical College which is a tertiary care centre located in Palpa district. Mental disorders are thought to impose a significant disease burden in developing as well as in developed regions of the world. ${ }^{1}$ These relapsing and remitting conditions are well recognized as contributors to impaired quality of life, disablement and increase consumption of health services. ${ }^{2}$ However in developing regions the primary focus is upon malnutrition and infectious disease. Mental disorders are not given due priority.

In 1909, Adolf Meyer advocated management of mentally ill patients outside the mental hospitals and proposed a community mental health approach. A unit of psychiatry OPD in general hospital would have an advantage over the mental hospital, because they would be easily accessible, approachable without stigma and would facilitate treatment for mental health 
problems. Positive trends in psychiatric help seeking can be directly linked to the advantage offered by a general hospital psychiatric unit. The stigma attached to the mental illness presents a serious barrier not only to diagnosis and treatment of mental disorders but to accept them in community. Till now maximum people are out of modern treatment facility due to poor economic conditions, prevailing superstition, stigma in mental patients and lack of scientific method of treatment of mental illness. ${ }^{3}$ The aim of this study was documentation of psychiatry morbidity seeking treatment in psychiatry OPD of tertiary care level and comparing the pattern of psychiatry morbidity with other published literature.

\section{MATERIAL AND METHOD}

This is a retrospective study based on the data recorded in the psychiatry department of Lumbini Medical College Teaching Hospital. Data of all patients attending in psychiatric OPD were included in the study. The time period covered was from October 29, 2014 to December 29, 2014. Demographic data and diseases profile of 107 new patients attending the OPD were analyzed. The ratios and proportions were used for statistical analysis. The rapport was established with the patients to obtain enough information. The semi structured Pro forma was filled with adequate information. The Pro forma comprised of name, age, sex, marital status, education and occupation. Questions related with complaints of the patient were taken which included chief complaints, history of present illness, past history, family history. The patients were examined in a detailed manner, which included general examination, systemic examination and mental status examination. ICD-10 DCR diseases diagnosis code was strictly followed.

\section{RESULT}

Out of 107 patients, $60.74 \%$ (65) were females and $39.26 \%$ (42) were males. Male to female ratio was 0.69:1 showing female predominance.

Patients of age group 31-40yrs showed the largest proportion (27.49\%) followed by age group 41-50yrs $(24.29 \%)$ (Table-1). The highest proportion of the cases were illiterate $(69.15 \%)$ followed by primary level of education (14.95\%). (Table 2) Most of the cases were household work
(35.51\%) followed by farmers (31.77\%). (Table 3) Anxiety disorder $(27.10 \%)$ was the most frequent diagnosis ahead of "Others" (18.69\%) followed by depressive disorder (15.88\%). (Table 4)

Table 1: Age wise Distribution Of Patients

\begin{tabular}{|l|l|l|l|l|}
\hline $\begin{array}{l}\text { Age } \\
\text { Group }\end{array}$ & Male & Female & Total & Percentage \\
\hline $0-10$ & - & - & - & - \\
\hline $11-20$ & 7 & 6 & 13 & 12.14 \\
\hline $21-30$ & 12 & 11 & 23 & 21.49 \\
\hline $31-40$ & 14 & 15 & 29 & 27.10 \\
\hline $41-50$ & 4 & 22 & 26 & 24.29 \\
\hline $51-60$ & 2 & 2 & 4 & .03 \\
\hline$>61$ & 3 & 9 & 12 & 11.21 \\
\hline Total & 42 & 65 & 107 & 100 \\
\hline
\end{tabular}

Table 2: Distribution Of Patients according to educational Level

\begin{tabular}{|l|l|l|}
\hline Education level & Frequency & $\%$ \\
\hline Illiterate & 74 & 69.15 \\
\hline Primary & 16 & 14.95 \\
\hline Middle & 10 & 9.34 \\
\hline SLC & 5 & 4.67 \\
\hline $10+2$ and above & 2 & 1.86 \\
\hline Total & 107 & 100 \\
\hline
\end{tabular}

Table 3: Distribution Of Patients according to Occupation

\begin{tabular}{|l|l|l|}
\hline Occupation & Frequency & Percentage \\
\hline Farmer & 34 & 31.77 \\
\hline Household work & 38 & 35.51 \\
\hline Service holder & 18 & 16.82 \\
\hline Business & 2 & 1.86 \\
\hline Student & 13 & 12.14 \\
\hline Unemployed & 2 & 1.86 \\
\hline Total & 107 & 100 \\
\hline
\end{tabular}

\section{DISCUSSION}

Studies have revealed that four of the six leading causes of years lived with disability are due to neuropsychiatric disorders (depression, alcohol-use disorders, schizophrenia and bipolar disorder). ${ }^{2}$ These disorders account for greater morbidity than mortality in patients and therefore directly related to impaired quality of life. Many studies have been conducted in developed countries and some in developing 
countries attempting to study the pattern of neuropsychiatric illness in outpatient settings and in inpatients.

\section{$\underline{\text { Table 4: Diagnostic Distribution Of Patients }}$}

\begin{tabular}{|l|l|l|l|}
\hline $\begin{array}{l}\text { ICD-10 } \\
\text { code }\end{array}$ & Diagnosis & Frequency & Percentage \\
\hline F-45 & $\begin{array}{l}\text { Somatoform } \\
\text { disorder }\end{array}$ & 9 & 8.41 \\
\hline F-41.3 & $\begin{array}{l}\text { Mixed anxiety } \\
\text { depression }\end{array}$ & 6 & 5.60 \\
\hline G-40 & Seizure disorder & 5 & 4.67 \\
\hline G-44 & $\begin{array}{l}\text { Migraine } \\
\text { headache }\end{array}$ & 3 & 2.80 \\
\hline F-32 & $\begin{array}{l}\text { Depressive } \\
\text { disorder }\end{array}$ & 17 & 15.88 \\
\hline F-41 & $\begin{array}{l}\text { Anxiety } \\
\text { disorder }\end{array}$ & 29 & 27.10 \\
\hline F-20 & Schizophrenia & 7 & 6.54 \\
\hline F-10 & $\begin{array}{l}\text { Alcohol } \\
\text { dependent } \\
\text { syndrome }\end{array}$ & 4 & 3.73 \\
\hline F-31 & BPAD & 2 & 1.86 \\
\hline F-44 & $\begin{array}{l}\text { Conversion } \\
\text { disorder }\end{array}$ & 3 & 2.80 \\
\hline F-29 & Psychosis-NOS & 2 & 1.86 \\
\hline & Others & 20 & 18.69 \\
\hline & Total & 107 & 100 \\
\hline
\end{tabular}

Our study showed that majority of patients suffering from psychiatry disorders were females $(60.74 \%)$. The cause for the same might be that majority of their husbands were abroad for earning money and they are left alone with the in-laws. The age group attending the psychiatry OPD were of 31-40yrs. The cause for the same can possibly be explained by midlife adult crisis and as they are the main earning member of the family. The majority of patients were illiterate $(69.17 \%)$. This represents the poor educational status of the whole country but especially in the mountainous region like Palpa and the neighbouring districts.

Almost one third of the subjects (35.51\%) were doing household work and being dependent on the income coming from their husbands working abroad. Others $(31.77 \%)$ were farmers. Anxiety disorders $(27.10 \%)$ was the most common diagnosis and depressive disorders $(15.88 \%)$ was the third .The second being others(18.69\%) which was our failure for fitting them into ICD-10 diagnosis. Schizophrenia and other psychosis were quite less in this area. The cause for psychosis not attending this college might be attributed to the trend of patients being taken by their relatives to the Terai region where older medical colleges were already established. Our psychiatry department is just flourishing and people are becoming gradually aware that our college is also capable of dealing with major psychiatric illnesses.

\section{CONCLUSION:}

We need to take seriously that there are a lot of new psychiatric cases attending psychiatry OPD as 107 new patients in a 2 month period is a large number. We need to advertise in the neighbouring districts about our full fledged psychiatry facility including electroconvulsive therapy in our college. We need to make the local people aware of the facilities and treatment available locally so that they need not look far for psychiatry services.

\section{REFERENCES:}

1. Ormel J, Non-Korff M, Ustune T. Common mental disorders and disability across cultures.JAMA 1994; 272:1741-48.

2. Shrestha MR, Pradhan S, Sharma S. Morbidity pattern of psychiatric disorders in patients seeking treatment in psychiatric OPD of private tertiary care hospital. Postgraduate Medical Journal of NAMS 2011;11:28-33.

3. Khan TA, Belbase M. Socio-demographic and clinical profile of patients attending a mental health camp: A study from Kanchanpur district of western Nepal. J Psychiatrists' Association of Nepal 2013;2(2):35-38. 